\title{
Effects of physical activity on systemic oxidative/DNA status in breast cancer survivors
}

\author{
BARBARA TOMASELLO $^{1}$, GIUSEPPE ANTONIO MALFA ${ }^{1}$, ANGELA STRAZZANTI ${ }^{2}$, \\ SANTI GANGI $^{2}$, CLAUDIA DI GIACOMO ${ }^{1}$, FRANCESCO BASILE ${ }^{2}$ and MARCELLA RENIS ${ }^{1}$ \\ ${ }^{1}$ Department of Drug Sciences, Section of Biochemistry, University of Catania, I-95125 Catania; \\ ${ }^{2}$ Department of Surgery, University of Catania, I-95124 Catania, Italy
}

Received June 24, 2016; Accepted September 2, 2016

DOI: $10.3892 / 01.2016 .5449$

\begin{abstract}
Physical activity offers a paradoxical hormetic effect and a health benefit to cancer survivors; however, the biochemical mechanisms have not been entirely elucidated. Despite the well-documented evidence implicating oxidative stress in breast cancer, the association between health benefits and redox status has not been investigated in survivors who participate in dragon boating. The present study investigated the plasmatic systemic oxidative status (SOS) in breast cancer survivors involved in two distinct physical training exercises. A total of 75 breast cancer survivors were allocated to one of three groups: Control (resting), dragon boat racing and walking group; the latter is a type of aerobic conditioning exercise often advised to cancer patients. Various biochemical oxidative stress markers were examined, including oxidant status (hydroperoxide levels, lipid oxidation) and antioxidant status (enzymatic activities of superoxide dismutase and glutathione peroxidase, reduced glutathione levels and antioxidant capability). In addition, the individual DNA fragmentation and DNA repair capability of nucleotide excision repair (NER) systems were examined by comet assays. According to the results, all patients exhibited high levels of oxidative stress. Physical activity maintained this oxidative stress condition but simultaneously had a positive influence on the antioxidant component of the SOS, particularly in the dragon boat racing group. DNA fragmentation, according to the levels of singleand double-strand breaks, were within the normal range in the two survivor groups that were involved in training activities. Radiation-induced damage was not completely recognised or repaired by NER systems in any of the patients, probably leading to radiosensitivity and/or susceptibility of patients to
\end{abstract}

Correspondence to: Professor Marcella Renis, Department of Drug Sciences, Section of Biochemistry, University of Catania, 6 Viale Andrea Doria, I-95125 Catania, Italy

E-mail: renis@unict.it

Key words: systemic oxidative status, comet assay, dragon boating, breast cancer, nucleotide excision repair, superoxide dismutase activity, glutathione cancer. These findings suggest that physical activity, particularly dragon boat racing, that modulates SOS and DNA repair capability could represent a strategy for enhancing the quality of life and improving the long-term health benefits for breast cancer survivors.

\section{Introduction}

Breast cancer is a leading cause of cancer-associated mortalities among women worldwide. Risk factors, in addition to familial history and chromosomal instability, include diet and lifestyle, high body weight, oral contraception, age at menarche/menopause/first pregnancy, and oestrogen treatment (1). Previous data supports a causative role of oxidative stress in breast cancer development and a paradoxical effect elicited by physical activity, which increases the production of reactive oxygen species (ROS), as well as increasing antioxidant capabilities in order to counteract subsequent oxidative insults (2). ROS are dual-faceted molecules. Whereas modest levels are useful as cell signalling molecules in various physiological cellular processes, including proliferation, apoptosis, differentiation, migration, invasion and angiogenesis (3), high levels cause severe oxidative damage to cell components, such as lipids, proteins and DNA $(4,5)$.

Antioxidants counteract increases in the production of free radicals, protect the body from oxidative damage by maintaining redox balance, and are critical for preserving optimum health and well-being. Antioxidant defence mechanisms may be enzymatic [superoxide dismutase (SOD), catalase, glutathione peroxidase (GPx)] or non-enzymatic (vitamins and/or certain polyphenol molecules introduced through diet); for example, reduced glutathione (GSH) is particularly able to scavenge hydrogen peroxide. When ROS production occurs in the absence of sufficient defence mechanisms, a number of harmful genomic modifications may occur, including chromosomal instability, permanent DNA damage and acquisition of mutations, which may also be disposed by alterations in DNA repair systems; this can contribute to the development of various diseases, including carcinogenesis (6).

Numerous studies have indicated that upper body exercise programs, and particularly dragon boat racing, in association with cancer therapy (7) may confer benefits to cancer patients, including improving emotional and physical functioning, 
decreasing treatment-induced symptoms (such as nausea, fatigue or pain) and problems associated with lymphedema (8), and improving survival and quality of life. However, little is known about the biochemical/clinical factors underlying such health benefits, such as the improvement in oxidative stress pathways induced by physical activity $(9,10)$. To date, to the best of our knowledge, no studies of the association between dragon boat racing and oxidative stress have been conducted.

Considering the contribution of regular exercise to ROS production and the subsequent biological adaptation by enhanced antioxidant enzymatic capacity (11), the present study focused on the possible association between redox status and physical activity by examining oxidant and antioxidant biomarkers in 75 breast cancer survivors involved in one of two training programs [dragon boat racing $(n=25)$ or walking $(n=25)]$ or at rest $(n=25)$. Walking as well as jogging, cycling and swimming are examples of aerobic conditioning exercise that the doctors advise to cancer patients as they may enhance physical well-being and improve recovery, in addition to enhancing cardiovascular fitness and effective weight management, all of which are beneficial to individuals with lymphedema (12).

In addition, in order to evidence a possible link between breast cancer susceptibility and DNA instability, individual DNA fragmentation and nucleotide excision repair (NER) DNA repair system capability were examined by comet assay.

\section{Materials and methods}

Experimental design and subjects. Breast cancer patients ( $n=75$; aged 35-65 years) were enrolled at the Department of Surgery of University of Catania (Catania, Italy). Additionally, healthy women ( $n=30$; aged $40-59$ years) were evaluated as control group. The characteristics of the population studied, including body mass index (BMI), age, height, weight and maximal oxygen consumption $\left(\mathrm{VO}_{2} \max \right)$ are reported in Table I. Smokers or patients with diabetes mellitus, liver disease, thyroid disease, nephrotic syndrome, hypertension and rheumatoid arthritis were not included in the study.

At $\sim 1$ month after commencing their individual therapeutic protocols, the cancer patients were separated into three groups depending on their freely chosen physical activity program (twice per week for $\geq 7$ months) or no activity, as follows: Dragon boat racing (Group $\mathrm{A}, \mathrm{n}=25$ ), walking (Group $B, n=25)$ and at rest (Control $\mathrm{BrC}, \mathrm{n}=25$ ). In the present experimental design the walking exercise consisted of walking briskly outdoors for 3-4 h a week along freely chosen paths.

All patients followed a controlled fruit/vegetable-rich diet. The patients were examined at different time points: i) before surgical treatment (BST); ii) after surgical treatment (AST); and iii) within 3 days after training.

The research protocol was granted ethical approval by the Hospital Committee for Research on Human Subjects and the written informed consent was obtained from each patient.

Blood samples. Blood samples obtained by venepuncture were centrifuged to collect either plasma (10 min at $800 \mathrm{x} g$ ) or lymphocytes by the Ficoll-Hypaque density gradient centrifugation method, as described below.
Derivatives of reactive oxygen metabolites ( $d$-ROMs) test. Plasma samples $(10 \mu \mathrm{l})$ were utilised to determine ROS levels by colorimetric d-ROMs test at a wavelength $(\lambda)$ of $505 \mathrm{~nm}$, according to the manufacturer's protocol (Diacron International srl, Grosseto, Italy). Colour intensity was expressed in Carratelli Units (CARR U), with 1 CARR U corresponding to $0.8 \mathrm{mg} / \mathrm{l}$ of hydrogen peroxide (13). Reference values of healthy subjects are 250-300 CARR U, while high/very high levels are in the range of 401-450 CARR U or >500 CARR U, respectively.

Biological plasmatic antioxidant potential (BAP) test. Individual antioxidant power was evaluated by measuring BAP. The BAP test (Diacron International srl) spectrophotometrically $(\lambda=504 \mathrm{~nm})$ measures the capacity of the plasma to reduce iron from the ferric form $\left(\mathrm{Fe}^{3+}\right)$ to the ferrous form $\left(\mathrm{Fe}^{2+}\right)(14)$. The results are expressed in $\mu \mathrm{mol} / \mathrm{l}$; reference values of healthy subjects are considered to be $>2,200 \mu \mathrm{mol} / 1$.

Determination of lipid hydroperoxides (LPO). Plasma LPO levels were evaluated by a modified ferrous oxidation/xylenol orange assay, at $\lambda=560 \mathrm{~nm}$, as described by Di Giacomo et al (15). The absorbance, measured by a Hitachi $\mathrm{U}-2000$ spectrophotometer, was expressed as $\mathrm{nmol} / \mathrm{ml}$ plasma using hydrogen peroxide $(0.2-20 \mu \mathrm{M})$ for calibration.

Total plasmatic thiol groups. Plasmatic thiol groups, containing predominantly reduced GSH, were determined spectrophotometrically at $\lambda=412 \mathrm{~nm}$ by Ellman's reagent [acid, 5,5'-dithiobis-(2-nitrobenzoic acid)] (15). Results are expressed as $\mu \mathrm{mol} / \mathrm{ml}$ of plasma.

Analysis of GPx activity. The analysis of plasmatic GPx was performed using a Glutathione Peroxidase Assay Kit, according to manufacturer's protocol (Cayman Chemical Company, Ann Arbor, MI, USA; item no. 703102), which refers to the Paglia and Valentine method (16). GPx activity was indirectly measured by a decrease in absorbance at $\lambda=340 \mathrm{~nm}\left(\mathrm{~A}_{340}\right)$ due to the oxidation of NADPH to NADP. Under conditions in which GPx activity is limiting, the rate of decrease in $A_{340}$ is directly proportional to GPx activity in the sample, expressed as $\mathrm{nmol} / \mathrm{min} / \mathrm{ml}$.

Analysis of SOD activity. The activity of all three types of SOD (Cu/Zn-, Mn- and Fe-SOD) was measured in plasma samples using a Superoxide Dismutase Assay Kit, according to the manufacturer's protocol (Cayman Chemical Company; item no. 706002), at 440-460 $\mathrm{nm}$ and expressed as $\mathrm{U} / \mathrm{ml}$; 1 unit of SOD is defined as the amount of enzyme required to have $50 \%$ conversion of the superoxide radical into molecular oxygen and hydrogen peroxide (17).

Alkaline and neutral comet assay. The alkaline and neutral Comet assay protocol was performed as previously described by Tomasello et al (18). Triplicate samples (each $40 \mu \mathrm{l}$ ) mixed with $0.5 \%$ low-melting point agarose were spread on FLARE ${ }^{\mathrm{TM}}$ Slides (Trevigen, Inc., Gaithersburg, MD, USA), immersed in cold lysis solution for $1 \mathrm{~h}$, and electrophoresed for $20 \mathrm{~min}$ in alkaline ( $\mathrm{pH}>13 ; 0.7 \mathrm{~V} / \mathrm{cm})$ or neutral buffer $(\mathrm{pH} 8 ; 0.5 \mathrm{~V} / \mathrm{cm})$. Following electrophoresis, slides were neutralised, dehydrated 
Table I. Characteristics of the enrolled subjects.

\begin{tabular}{lcc}
\hline Characteristic & $\begin{array}{r}\text { Healthy control } \\
\text { subjects }(\mathrm{n}=30)\end{array}$ & $\begin{array}{c}\text { Breast cancer } \\
\text { patients }(\mathrm{n}=75)\end{array}$ \\
\hline Age (years) & $49 \pm 9$ & $51 \pm 12$ \\
Height $(\mathrm{cm})$ & $160 \pm 5$ & $164 \pm 7$ \\
Weight $(\mathrm{kg})$ & $70 \pm 5$ & $68 \pm 4$ \\
Body mass index & $24 \pm 3$ & $23 \pm 5$ \\
Maximal oxygen & $40 \pm 3$ & $42 \pm 5$ \\
consumption $(\mathrm{ml} / \mathrm{kg} / \mathrm{min})$ & & \\
\hline
\end{tabular}

Data are presented as the mean \pm standard deviation.

by immersion in $70 \%$ ethanol and stained with SYBR Green. Analysis was conducted using an epifluorescence microscope (Leica Microsystems GmbH, Wetzlar, Germany) with Casp Comet Assay Software (version 1.2.2; CASPLab, University of Wroclaw, Poland), by measuring DNA damage as the percent of DNA in the comet Tail (\% TDNA). Each phase of the procedure was performed according to European Standards Committee on Oxidative DNA Damage guidelines (19). A CometAssay ${ }^{\circledR}$ Control Cell population from Trevigen, Inc. was co-electrophoresed.

Human umbilical vein endothelial cell (HUVEC) cultures, isolation of lymphocytes and DNA repair assay. Ultraviolet C (UVC)-induced cell damage and the efficacy of lymphocytes extracted from cancer survivors were tested on agarose-embedded HUVECs (Thermo Fisher Scientific, Inc., Waltham, MA, USA), cultured according to Russo et al (20). Confluent HUVECs were detached with trypsin-ethylenediaminetetraacetic acid, and the number of viable cells/ml was determine by trypan blue staining; only plates with total viable cells $\geq 70 \%$ were used for the NER Comet test, according to method proposed by Collins et al (21) and modified by Gaivão et al (22). The individual capability for NER of DNA from HUVECs damaged by UVC irradiation was measured to evaluating the activity of repair enzymes present in individual lymphocyte samples. Lymphocytes were isolated from heparinised venous blood on Ficoll-Hypaque gradients by centrifugation; lymphocytes extracted from each patient were prepared as described by Gaivão et al (22). Agarose-embedded HUVECs were irradiated with $1 \mathrm{Jm}^{-2} \mathrm{UVC}$ on ice; this creates pyrimidine dimers and 6,4-photoproducts, which are repaired by NER. Subsequently, the contents of the slides were lysed (pH 10.0-10.5; $2.5 \mathrm{M} \mathrm{NaCl}, 100 \mathrm{mM} \mathrm{Na} 2$ EDTA, $10 \mathrm{mM}$ Tris and $1 \%$ lauroyl sarcosine, $1 \%$ Triton X-100 and $10 \%$ dimethyl sulfoxide were added directly prior to use) at $4^{\circ} \mathrm{C}$ for $60 \mathrm{~min}$ to obtain naked DNA (17) and washed for $3 \times 5$ min with reaction buffer (40 mM HEPES, 0.1 M KCl, 0.5 mM EDTA, 1,6 mM $\mathrm{MgCl}_{2}, 0.2 \mathrm{mg} / \mathrm{ml}$ bovine serum albumin, adjusted to $\mathrm{pH} 8.0$ using $6 \mathrm{M} \mathrm{KOH})(21,22)$. Extracts $(45 \mu \mathrm{l})$ were added to each gel and incubated for $30 \mathrm{~min}$ in a humidified chamber at $37^{\circ} \mathrm{C}$. Reaction buffer alone was used as a negative control, and T4 endonuclease V (Trevigen, Inc.) was used as a positive control. Following incubation, the slides were processed according to the standard protocol for the alkaline comet assay to measure the DNA breaks introduced by the initial incision events of repair. The strand breaks produced were detected by comet assay; the increase in \% tail DNA over time reflects the DNA repair activity of the cell extract.

Statistical analysis. The data is presented as the mean \pm standard deviation in the tables and as median with interquartile range in the figures. The differences among the control groups and groups A and B were analysed by one-way analysis of variance. Statistical analysis was conducted using GraphPad Prism 5 statistical software (GraphPad Software, Inc., La Jolla, CA, USA). Boxplots were used to represent data and the differences between the individual groups were assessed with Bonferroni's post hoc test, with $\mathrm{P} \leq 0.05$ considered to indicate a statistically significant difference.

\section{Results}

Determination of SOS. The levels of oxidative and antioxidative parameters in the plasma of the subjects prior to training activity are shown in Table II. d-ROMs levels, a measure of oxidative status, differed significantly between the groups, being higher in the BST group (500 \pm 50 CARR U) compared with the control values of healthy women $(265 \pm 45$ CARR $\mathrm{U})$. The AST measures were significantly lower than those

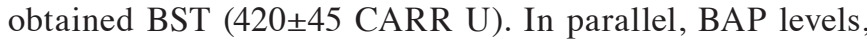
a measure of antioxidative status, were significantly lower compared with the control values in cancer patients (BST and AST patients).

In order to verify a possible link between oxidative stress conditions and physical activity in cancer, women affected by breast cancer were assessed in three groups: Group A (dragon boat racing), Group B (walking) and Control BrC (breast cancer survivors at rest). The following results regarding the SOS assessed are represented by boxplots, where the range of normal values derived from the healthy control group $(n=30)$ are indicated by the thick black line on the $y$-axis of each graph.

As shown in Fig. 1A, the levels of radical species were above the normal range of values; indeed, the majority of the examined subjects were in the high or very high range (between 400 and 550 CARR U). In particularly, ROS were induced by the two physical activities: $459 \pm 61$ CARR U for Group A and $502 \pm 76$ CARR U for Group B; however, this difference was not statistically significant $(\mathrm{P}=0.332)$. The increase in ROS was significant with respect to the Control $\mathrm{BrC}$ group for each of the two activity groups $(\mathrm{P}=0.038$ and $\mathrm{P}<0.001$, respectively).

As presented in Fig. 1B, the evaluation of LPO revealed higher levels in the three groups of cancer survivors compared with the healthy control values $(4.22 \pm 0.064 \mathrm{nmol} / \mathrm{ml} ; \mathrm{n}=30)$. The average values for Groups A and B were 13.2 \pm 3.6 and $15.08 \pm 2.7 \mathrm{nmol} / \mathrm{ml}$, respectively; the difference between these two activity groups was not statistically significant $(\mathrm{P}=0.224)$. Conversely, the differences between each of the physical activity groups and the Control $\mathrm{BrC}$ group $(9.7 \pm 2.5 \mathrm{nmol} / \mathrm{ml})$ were statistically significant $(\mathrm{P}=0.007$ and $\mathrm{P}<0.001$, respectively).

BAP data revealed that the majority of the subjects examined had a high plasmatic antioxidant potential $(2,275 \pm 337$ and 2,236 $\pm 223 \mu \mathrm{mol} / 1$ for Groups $\mathrm{A}$ and B, respectively), without a significant difference between the physical activity 
Table II. Results of systemic oxidative status tests in breast cancer patients and healthy controls, prior to commencing physical activity.

\begin{tabular}{lccc}
\hline Test & Control group $(\mathrm{n}=30)$ & BST group $(\mathrm{n}=75)$ & AST group $(\mathrm{n}=75)$ \\
\hline d-ROMs (CARR U) & $265 \pm 45$ & $500 \pm 50^{\mathrm{a}}$ & $420 \pm 45^{\mathrm{a}, \mathrm{b}}$ \\
BAP $(\mu \mathrm{mol} / \mathrm{l})$ & $2,380 \pm 200$ & $2,060 \pm 150^{\mathrm{a}}$ & $2,000 \pm 100^{\mathrm{a}}$ \\
\hline
\end{tabular}

Data are presented as the mean \pm standard deviation. ${ }^{\mathrm{a}} \mathrm{P}<0.05$ vs. control; ${ }^{\mathrm{b}} \mathrm{P}<0.05 \mathrm{vs}$. BST group. BST, before surgical treatment; AST, after surgical treatment; d-ROMs, derivatives of reactive oxygen metabolites; BAP, biological plasmatic antioxidant potential.
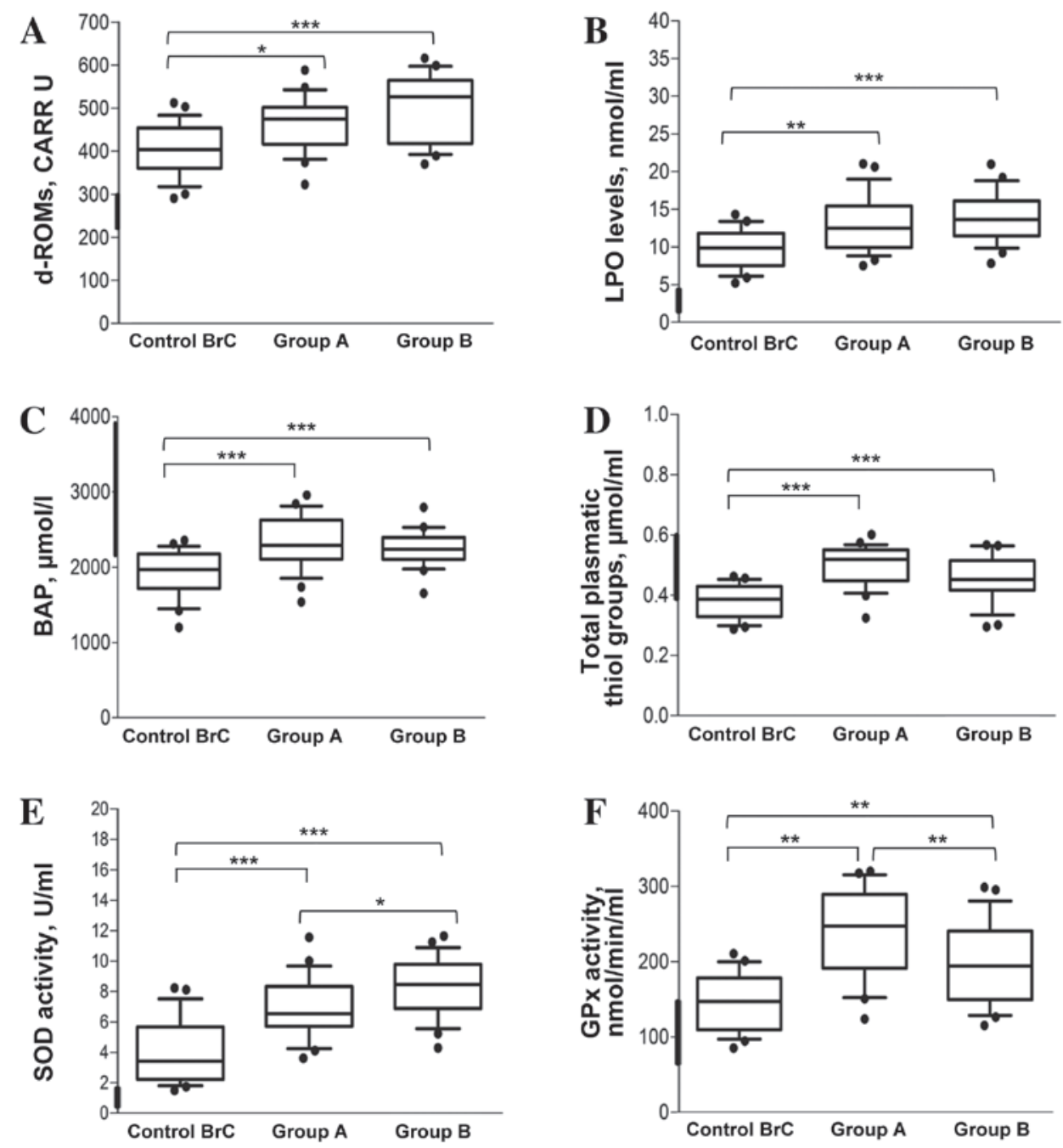

Figure 1. Determination of systemic oxidative status in breast cancer survivors. (A) d-ROMs test results; the levels of oxidative stress are expressed in CARR U (1 CARR U $=\mathrm{H}_{2} \mathrm{O}_{2} 0.08 \mathrm{mg} / \mathrm{dl}$; control range, 250-300 CARR U). (B) Plasmatic LPO levels are expressed as nmol $/ \mathrm{ml}$ (control range 8-10 nmol/ml). (C) BAP test represents the power of antioxidant capability and is expressed as $\mu \mathrm{mol} / 1$ (control range, $>2200 \mu \mathrm{mol} / \mathrm{l}$ ). (D) Total plasmatic thiol groups are expressed as $\mu \mathrm{mol} / \mathrm{ml}$ (control range, $0.4-0.6 \mu \mathrm{mol} / \mathrm{ml}$ ). (E) SOD activity is expressed as $\mathrm{U} / \mathrm{ml}$ (control values, $1.82 \pm 0.039 \mathrm{U} / \mathrm{ml}$ ). (F) GPx activity values are expressed in $\mathrm{nmol} / \mathrm{min} / \mathrm{ml}$ (control values, $113.41 \pm 20.77 \mathrm{nmol} / \mathrm{min} / \mathrm{ml}$ ). For each group, the line in the middle of the box represents the median, the black dash represents the mean value, and the lower and the upper edges of the box represent the 1st and 3rd quartiles, respectively. Whiskers represent the minimum and maximum values; observations denoted as black circles are considered outliers. The thick black line on the y-axis of the graph indicates the range of the healthy control group at rest $(\mathrm{n}=30) .{ }^{* * * *} \mathrm{P}<0.001 ;{ }^{* *} \mathrm{P}<0.01 ;{ }^{*} \mathrm{P}<0.05$. Group $\mathrm{A}$, dragon boat racing group; Group $\mathrm{B}$, walking group; Control BrC, breast cancer survivors at rest; d-ROMs, derivatives of reactive oxygen metabolites; LPO, lipid hydroperoxides; BAP, biological plasmatic antioxidant potential; SOD, superoxide dismutase; GPx, glutathione peroxidase.

groups (Fig. 1C). Additionally, following physical training, BAP levels were significantly increased compared with pre-exercise basal levels $(2,000 \pm 100 \mu \mathrm{mol} / 1$, refer to AST values in Table II) and control $\mathrm{BrC}$ levels.
In addition, as shown in Fig. 1D, the total plasmatic thiol levels all three cancer survivor groups overlapped with the range of values from control group $(0.4-0.6 \mu \mathrm{mol} / \mathrm{ml})$, and no statistically significant differences were identified between 
the two physical activity groups $(\mathrm{P}=0.173)$. However, the thiol levels in a proportion of the women in Group B and Control $\mathrm{BrC}$ were below the levels of the control. The Control $\mathrm{BrC}$ values were also significantly lower than those of the two physical activity groups (both $\mathrm{P}<0.001$ ).

The estimated SOD activity in each of the cancer survivor groups (Fig. 1E), was markedly higher than control values $(1.82 \pm 0.039 \mathrm{U} / \mathrm{ml})$. In particular, the activity of this enzyme was statistically significantly higher in Group B compared with that in Group A $(8.4 \pm 1.9$ vs. $6.8 \pm 2 \mathrm{U} / \mathrm{ml} ; \mathrm{P}=0.044)$, as well as compared with that in the Control BrC group, which was the lowest $(3.90 \pm 2.04$, both $\mathrm{P}<0.001)$.

GPx activity levels were significantly higher in the two physical activity groups relative to the healthy control values $(113.41 \pm 20.77 \mathrm{nmol} / \mathrm{min} / \mathrm{ml}$, both $\mathrm{P}<0.001)$ and the Control BrC group (147.10 $\pm 37.6 \mathrm{nmol} / \mathrm{min} / \mathrm{ml}, \mathrm{P}=0.007$ for Group A and $\mathrm{P}=0.007$ for Group B). In particular, the level in Group A was $246 \pm 57.7 \mathrm{nmol} / \mathrm{min} / \mathrm{ml}$, while in Group B a slightly lower mean of $197 \pm 53.3 \mathrm{nmol} / \mathrm{min} / \mathrm{ml}$ was observed (Fig. 1F).

DNA damage and DNA repair capability. The results regarding DNA fragmentation, measured with alkaline and neutral versions of the comet assay, are presented as \% TDNA in Fig. 2A and B. The alkaline comet assay data revealed that DNA damage was higher in Group B (17.10\%) compared with in Group A (14.05\%), and the damage in each of these two groups was lower than in the Control BrC group (19.59\%). However no statistical significance was observed among the groups. Additionally, the majority of subjects had \% TDNA values within the range considered 'normal' for the comet assay (22). Conversely, very little double-strand break DNA damage was indicated by the neutral comet assay analysis for all groups, as shown in Fig. 2B.

The NER analysis revealed no significant difference in \% TDNA between the two physical activity groups (Group A, $31.5 \pm 7.6$ vs. Group B, $30.3 \pm 8.4 \%$; $\mathrm{P}=0.80$ ); however, the individual repair capabilities were below that calculated with $\mathrm{T} 4$ endonuclease $\mathrm{V}$, which was used as the reference value in the present study (\% TDNA, 70\%; dotted line in Fig. 3). The two physical activity groups exhibited significantly greater repair capabilities compared with the Control $\mathrm{BrC}$ group $(24.5 \pm 6 \%)$ following UVC-induced damage (Group A, $\mathrm{P}=0.008$; Group B, $\mathrm{P}=0.045)$.

\section{Discussion}

One adverse outcome of surgical or radiologic breast cancer treatment is the risk of lymphedema. Onset may occur months or years following treatment for breast cancer; survivors remain at risk for life so to prevent postoperative development, vigorous repetitive movements of the upper limbs was strongly discouraged until $\sim 10$ years ago $(23,24)$. However, more recently doctors have encouraged the practice of physical activity at least six months post-treatment, for blocking lymphedema development, in addition to beneficial effects that the practice of stable and diversified physical activity exhibits in preventing carcinogenesis, in ameliorating various symptoms associated with chemotherapeutic treatment, improving the quality of life and resilience of survivors, and decreasing levels of distress $(24,25)$. However, to the best of our knowledge, no
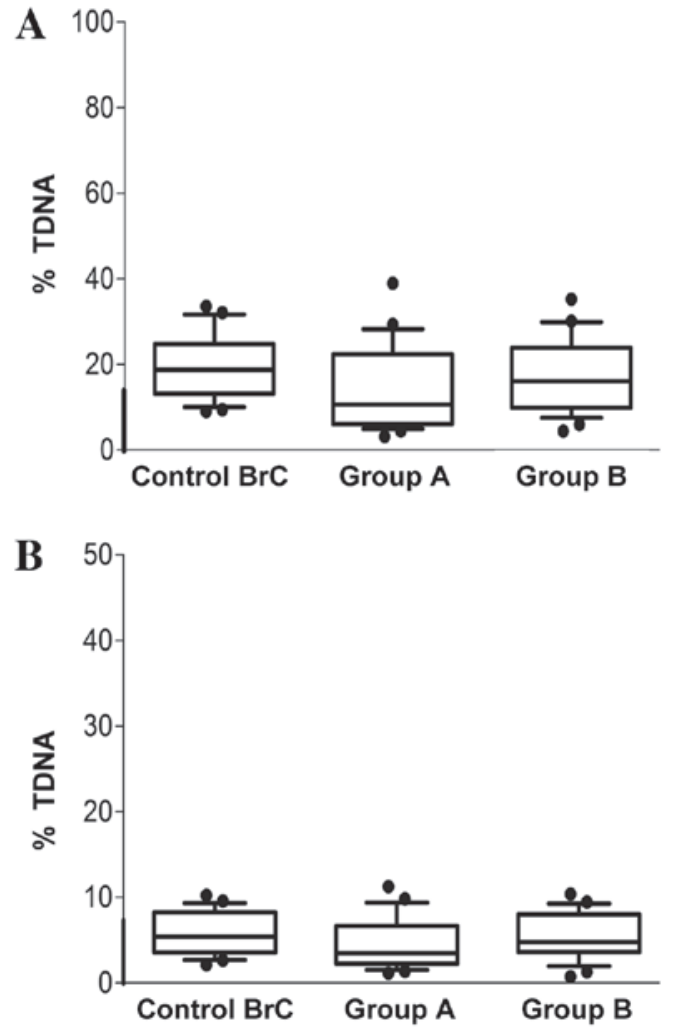

Figure 2. DNA damage in breast cancer survivors. (A) Total DNA damage measured by alkaline and (B) double-strand breaks measured by neutral comet assays following physical training (Groups A and B) or rest (Control $\mathrm{BrC})$. The results are expressed as \% TDNA, i.e. the percentage of DNA in the comet tail. For each group, the line in the middle of the box represents the median, the black dash represents the mean value, and the lower and the upper edges of the box represent the 1st and 3rd quartiles, respectively. Whiskers represent the minimum and maximum values; observations denoted as black circles are considered outliers. The thick black line on y-axis of the graph indicates the range of control values. Group A, dragon boat racing group; Group B, free walking group; Control BrC, breast cancer survivors at rest.

useful data have been reported regarding the biochemical changes that underlie the improved health of cancer survivors who participate in upper body exercise programs such as dragon boating.

Numerous previous studies have documented an interference in 'redox regulation' associated with carcinogenesis, tumour progression and/or chemotherapeutic efficacy, including in breast cancer $(2,26)$. In order to investigate the association between physical activity and oxidative stress-related biochemical parameters in breast cancer survivors, the present study assessed two groups of breast cancer patients involved in different physical activities twice per week: dragon boat racing (Group A) and walking (Group B).

Current opinions regarding the various indices that may be used to measure the oxidative status of patients are controversial. Such indices include total antioxidant capability (TAS or BAP test), total oxidative status (TOS), and the TAS/TOS ratio, which is expressed as the oxidative stress index. The latter of these indices is considered as the best approach for determining the net oxidative stress condition, at a diagnostic and/or therapeutic level (27).

In the present study, various oxidative stress biomarkers were evaluated. First, measurements of ROS levels (d-ROMs 


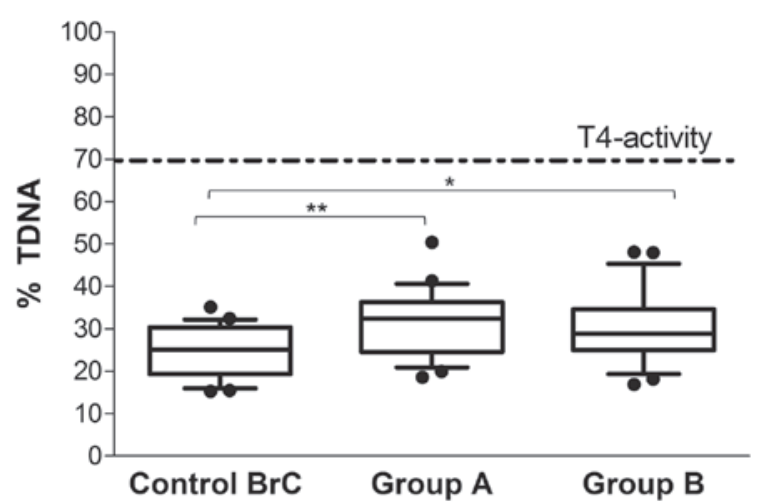

Figure 3. Nucleotide excision repair capability in breast cancer survivors. Naked DNA from ultraviolet C-irradiated human umbilical vein endothelial cells were incubated in gel with buffer, or T4 endonuclease V, or lymphocyte extracts from each subject. Following $45 \mathrm{~min}$ of incubation, DNA breaks introduced by repair endonuclease activity in the lymphocyte extracts were measured by comet assay and expressed as \% TDNA, i.e. the percentage of DNA in the comet Tail. For each group, the line in the middle of the box represents the median, the black dash represents the mean value, and the lower and the upper edges of the box represent the 1st and 3rd quartiles, respectively. Whiskers represent the minimum and maximum values; observations denoted as black circles are considered outliers. The dotted line represents the calculated \% TDNA (percentage of DNA in the comet tail) from T4 endonuclease $\mathrm{V}$, which was considered as reference value for evaluating patients repair capability. ${ }^{* *} \mathrm{P}<0.01 ;{ }^{*} \mathrm{P}<0.05$. Group $\mathrm{A}$, dragon boat racing group; Group B, walking group; Control BrC, breast cancer survivors at rest.

test, which is similar to TOS) and antioxidant capability (BAP test, which is similar to TAS) were taken in patient groups BST and AST. Secondly, following the physical training programs, in addition to the aforementioned parameters, the plasmatic LPO and GSH levels and the enzymatic activities of SOD and GPx were examined in the breast cancer survivors. Furthermore, DNA status and repair capability in the experimental groups were explored. The present data demonstrated that enhanced oxidative stress was present at time of diagnosis in all enrolled subjects, which is in agreement with data from a number of previous studies $(28,29)$, affecting both components of SOS. Certain authors have reported that the activities of all the studied antioxidant enzymes (SOD, catalase, GPx and glutathione S-transferases) and the levels of reduced GSH were significantly increased in breast cancer patients compared with their healthy control group (30); whereas others have reported reduced SOD and GPx activities in breast cancer patients (31). In the present study, the oxidative stress level was improved marginally following surgical treatment, and was positively affected by physical activities, but in different ways in the two survivor groups who undertook training programs. Enzymatic and non-enzymatic antioxidants, as well as lipid peroxidation, have been reported to be altered among various tissues types and individual breast cancer patients $(32,33)$. In the present study, in the presence of elevated levels of ROS (based on the d-ROMs test), high levels of LPO levels were observed following physical training. This ROS increase positively influences the plasmatic antioxidant component (BAP), and may be considered a direct reaction to a physical activityinduced oxidative environment.

In the present study, despite the high ROS production, the total plasmatic thiol group levels, comprising mainly GSH, were not depleted but were maintained within the reference normal range, being higher in Group A than in Group B. This data demonstrates the benefits of physical activity, as previously reported in other studies $(34,35)$. We consider that the high level of GSH, as well as the GPx and SOD activity, may be generated to counteract the effects of increased oxidative stress and lipoperoxidation, as an adaptive response to the increase in circulating ROS; this was also reported by Carter et al (36). Such an adaptive response, mediated by a physical activity-induced oxidative environment, may involve changes in antioxidant gene expression via the antioxidant-responsive elements, which may be consistent with the enhanced enzyme activities observed as previously reported by Kobayashi et al (37). Furthermore, in our opinion, the maintenance of high antioxidant levels observed in the studied patients is the result of the diet rich in vegetables/fruit and the physical activity, as reported in a previous study (38).

Certain previous studies have reported the presence of higher baseline DNA damage in breast cancer patients without physical training $(39,40)$. The present results regarding double-strand break DNA damage (neutral comet assay) indicated that the \% TDNA values were similar in all breast cancer patients and were comparable with healthy control values. A similar finding was observed in the majority of women in both groups that underwent training programs when using the alkaline comet assay, although some patients exhibited values higher than that of the reference control. These data may be associated with possible persistent DNA damage and non-functional/inefficient DNA repair systems.

It is well-known that most damage is removed by repair enzymes before it is able to interfere with DNA replication and introduce mutations. Individual variation in DNA repair capacity is therefore likely to be an important factor in determining cancer risk. In the present study, the DNA-NER capability, represented by the activity of lymphocyte extracts, was less than the T4 enzyme-treated control in all of the studied women. In particular, the specific lesions that occur following UVC radiation exposure, which are recognised and excised by $\mathrm{T} 4$ endonuclease (1 unit), produced an increase in $\%$ TDNA equal to $70 \%$ over time, reflecting the maximum DNA repair activity. By contrast, the lymphocyte extract of the breast cancer patients exhibited repair capacities equal to 31.04 and $30.15 \%$ for Groups A and B, respectively. This data demonstrates that almost half of radiation-induced damage was not repaired by the enzyme activity of the lymphocyte extracts, and remained as persistent lesions. Shahidi et al (41), who used a kinetic repair approach, demonstrated the radiation-induced DNA damage is not completely repaired compared with control subjects after $3 \mathrm{~h}$, leading us to hypothesise that deficient radio-induced damage repair may promote the onset of late harmful irradiation effects in breast cancer patients.

One limitation of this in vitro assay is that the lymphocytes are not directly irradiated, and the NER system is perhaps not sufficiently activated, which may have produced the deficient repair activity observed. Similarly to Gaivão et al (22), who performed an NER-assay on healthy subjects, inter-individual variability of repair activity in cancer survivors was observed in the present study; this may arise from genetic polymorphisms and epigenetic factors, 
thus influencing individual susceptibility to cancer development. In our opinion, the present data is of interest, although the experimental approach must be repeated and extended to a larger number of samples, particularly because this data may be useful in the context of individual radiosensitivity in women with breast cancer for whom radiotherapy is chosen as a treatment. Considering this data on DNA repair, we hypothesise that dragon boating and continuity of physical activity, inducing ROS production, may stimulate an increase in DNA repair ability over time, among the possible adaptive responses; this is also in agreement with Mao et al (42).

In conclusion, the present data indicates that the measurement of different blood redox biomarkers may be a useful approach in defining an individual antioxidant therapy to support and/or reinforce the efficacy of primary treatments; that the monitoring of DNA repair capacity (in particular the NER system) may be useful in defining an eventual radiotherapeutic plan; and that dragon boating is beneficial for breast cancer survivors, leading us to suggest the large scale adoption of this activity, since it may also lead to considerable savings in costs associated with physiotherapy.

\section{Acknowledgements}

The authors would like to thank Mr. David Shanahan, an independent native English translator, for proofreading the manuscript in English.

\section{References}

1. Carlson RW, Allred DC, Anderson BO, Burstein HJ, Carter WB Edge SB, Erban JK, Farrar WB, Goldstein LJ, Gradishar WJ, et al: Breast cancer. Clinical practice guidelines in oncology. J Natl Compr Canc Netw 7: 122-192, 2009.

2. Acharya A, Das I, Chandhok D and Saha T: Redox regulation in cancer: A double-edged sword with therapeutic potential. Oxid Med Cell Longev 3: 23-34, 2010.

3. Martin KR and Barrett JC: Reactive oxygen species as double-edged swords in cellular processes: Low-dose cell signaling versus high-dose toxicity. Hum Exp Toxicol 21: 71-75, 2002.

4. Cooke MS, Evans MD, Dizdaroglu M and Lunec J: Oxidative DNA damage: Mechanisms, mutation, and disease. FASEB J 17: $1195-1214,2003$

5. Klaunig JE, Kamendulis LM and Hocevar BA: Oxidative stress and oxidative damage in carcinogenesis. Toxicol Pathol 38 96-109, 2010.

6. Scott TL, Rangaswamy S, Wicker CA and Izumi T: Repair of oxidative DNA damage and cancer: Recent progress in DNA base excision repair. Antioxid Redox Signal 20: 708-726, 2014.

7. McCausland LL: Dragon boat racing: Life after breast cancer treatment. Am J Nurs 110: 48-54, 2010.

8. Hull MM: Lymphedema in women treated for breast cancer. Semin Oncol Nurs 16: 226-237, 2000.

9. Bouillet T, Bigard X, Brami C, Chouahnia K, Copel L, Dauchy S, Delcambre C, Descotes JM, Joly F, Lepeu G, et al: Role of physical activity and sport in oncology: Scientific commission of the National Federation Sport and Cancer CAMI. Crit Rev Oncol Hematol 94: 74-86, 2015.

10. Knop K, Schwan R, Bongartz M, Bloch W, Brixius K and Baumann F: Sport and oxidative stress in oncological patients. Int J Sports Med 32: 960-964, 2011.

11. McCullough LE, Santella RM, Cleveland RJ, Bradshaw PT, Millikan RC, North KE, Olshan AF, Eng SM, Ambrosone CB, Ahn J, et al: Polymorphisms in oxidative stress genes, physical activity, and breast cancer risk. Cancer Causes Control 23: 1949-958, 2012.

12. NLN Medical Advisory Committee: Position statement of the National Lymphedema Network: exercise. San Francisco: National Lymphedema Network, 2013.
13. Trotti R, Carratelli M and Barbieri M: Performance and clinical application of a new, fast method for the detection of hydroperoxides in serum. Panminerva Med 44: 37-40, 2002.

14. Benzie IF and Strain JJ: The ferric reducing ability of plasma (FRAP) as a measure of 'antioxidant power': The FRAP assay. Anal Biochem 239: 70-76, 1996.

15. Di Giacomo C, Acquaviva R, Sorrenti V, Vanella A, Grasso S, Barcellona ML, Galvano F, Vanella L and Renis M: Oxidative and antioxidant status in plasma of runners: Effect of oral supplementation with natural antioxidants. J Med Food 12: 145-150, 2009.

16. Paglia DE and Valentine WN: Studies on the quantitative and qualitative characterization of erythrocyte glutathione peroxidase. J Lab Clin Med 70: 158-169, 1967.

17. Sandström J, Nilsson P, Karlsson K and Marklund SL: 10-fold increase in human plasma extracellular superoxide dismutase content caused by a mutation in heparin-binding domain. J Biol Chem 269: 19163-19166, 1994.

18. Tomasello B, Grasso S, Malfa G, Stella S, Favetta M and Renis M: Double-face activity of resveratrol in voluntary runners: Assessment of DNA damage by comet assay. J Med Food 15: 441-447, 2012.

19. European Standards Committee on Oxidative DNA Damage (ESCODD): Measurement of DNA oxidation in human cells by chromatographic and enzymic methods. Free Radic Biol Med 34: 1089-1099, 2003

20. Russo A, Palumbo M, Aliano C, Lempereur L, Scoto G and Renis M: Red wine micronutrients as protective agents in Alzheimer-like induced insult. Life Sci 72: 2369-2379, 2003.

21. Collins AR, Dusinská M, Horváthová E, Munro E, Savio M and Stĕtina R: Inter-individual differences in repair of DNA base oxidation, measured in vitro with the comet assay. Mutagenesis 16: 297-301, 2001.

22. Gaivão I, Piasek A, Brevik A, Shaposhnikov S and Collins AR: Comet assay-based methods for measuring DNA repair in vitro; estimates of inter- and intra-individual variation. Cell Biol Toxicol 25: 45-52, 2009.

23. Harris SR and Niesen-Vertommen SL: Challenging the myth of exercise-induced lymphedema following breast cancer: A series of case reports. J Surg Oncol 74: 95-99, 2000.

24. Fu MR, Ridner SH and Armer J: Post-breast cancer. Lymphedema: Part 1. Am J Nurs 109: 48-54; quiz 55, 2009.

25. Mandelblatt JS, Luta G, Kwan ML, Makgoeng SB, Ergas IJ, Roh JM, Sternfeld B, Adams-Campbell LL and Kushi LH: Associations of physical activity with quality of life and functional ability in breast cancer patients during active adjuvant treatment: The Pathways Study. Breast Cancer Res Treat 129: 521-529, 2011.

26. Vera-Ramirez L, Sanchez-Rovira P, Ramirez-Tortosa MC, Ramirez-Tortosa CL, Granados-Principal S, Lorente JA and Quiles JL: Free radicals in breast carcinogenesis, breast cancer progression and cancer stem cells. Biological bases to develop oxidative-based therapies. Crit Rev Oncol Hematol 80: 347-368, 2011.

27. Aslan R, Kutlu R, Civi S and Tasyurek E: The correlation of the total antioxidant status (TAS), total oxidant status (TOS) and paraoxonase activity (PON1) with smoking. Clin Biochem 47: 393-397, 2014.

28. Shen J, Gammon MD, Terry MB, Wang Q, Bradshaw P, Teitelbaum SL, Neugut AI and Santella RM: Telomere length, oxidative damage, antioxidants and breast cancer risk. Int $\mathrm{J}$ Cancer 124: 1637-1643, 2009.

29. Fortner RT, Tworoger SS, Wu T and Eliassen AH: Plasma florescent oxidation products and breast cancer risk: Repeated measures in the Nurses' Health Study. Breast Cancer Res Treat 141: 307-316, 2013.

30. Rajneesh CP, Manimaran A, Sasikala KR and Adaikappan P: Lipid peroxidation and antioxidant status in patients with breast cancer. Singapore Med J 49: 640-643, 2008

31. Abiaka C, Al-Awadi F, Al-Sayer H, Gulshan S, Behbehani A and Farghally M: Activities of erythrocyte antioxidant enzymes in cancer patients. J Clin Lab Anal 16: 167-171, 2002.

32. Kasapović J, Pejić S, Todorović A, Stojiliković V and Pajović SB: Antioxidant status and lipid peroxidation in the blood of breast cancer patients of different ages. Cell Biochem Funct 26: 723-730, 2008.

33. Hasan HR, Mathkor TH and Al-Habal MH: Superoxide dismutase isoenzyme activities in plasma and tissues of Iraqi patients with breast cancer. Asian Pac J Cancer Prev 13: 2571-2576, 2012.

34. Gago-Dominguez M, Jiang X and Esteban Castelao J: Lipid peroxidation and the protective effect of physical exercise on breast cancer. Med Hypotheses 68: 1138-1143, 2007.

35. Balneaves LG, Van Patten C, Truant TL, Kelly MT, Neil SE and Campbell KL: Breast cancer survivors' perspectives on a weight loss and physical activity lifestyle intervention. Support Care Cancer 22: 2057-65, 2014. 
36. Carter CL, Onicescu G, Cartmell KB, Sterba KR, Tomsic J, Fox T, Dunmeyer E and Alberg AJ: Factors associated with cancer survivors' selection between two group physical activity programs. J Cancer Surviv 4: 388-398, 2010.

37. Kobayashi M and Yamamoto M: Molecular mechanisms activating the Nrf2-Keap1 pathway of antioxidant gene regulation. Antioxid Redox Signal 7: 385-394, 2005.

38. Carayol M, Romieu G, Bleuse JP, Senesse P, Gourgou-Bourgade S, Sari C, Jacot W, Sancho-Garnier H, Janiszewski C, Launay S, et al: Adapted physical activity and diet (APAD) during adjuvant breast cancer therapy: Design and implementation of a prospective randomized controlled trial. Contemp Clin Trials 36: 531-543, 2013.

39. Sánchez P, Peñarroja R, Gallegos F, Bravo JL, Rojas E and Benítez-Bribiesca L: DNA damage in peripheral lymphocytes of untreated breast cancer patients. Arch Med Res 35: 480-483, 2004.
40. Hussien MM, McNulty H, Armstrong N, Johnston PG, Spence RA and Barnett Y: Investigation of systemic folate status, impact of alcohol intake and levels of DNA damage in mononuclear cells of breast cancer patients. Br J Cancer 92: 1524-1530, 2005.

41. Shahidi M, Mozdarani H and Bryant PE: Radiation sensitivity of leukocytes from healthy individuals and breast cancer patients as measured by the alkaline and neutral comet assay. Cancer Lett 257: 263-273, 2007

42. Mao Z, Hine C, Tian X, Van Meter M, Au M, Vaidya A, Seluanov A and Gorbunova V: SIRT6 promotes DNA repair under stress by activating PARP1. Science 332: 1443-1446, 2011. 